
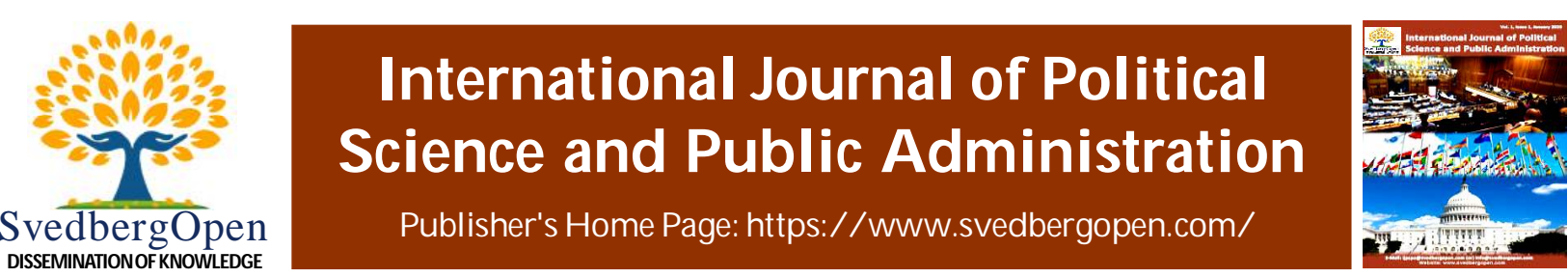

Research Paper

O pen A ccess

\title{
Social Media, Disinformation, and the 2022 BARMM Parliamentary Elections
}

\author{
Michael Henry LL. Yusingco ${ }^{1 *}$ \\ ${ }^{1}$ Ateneo Policy Center, School of Government, Ateneo de Manila University, Quezon City, 1108 Metro Manila, Philippines. \\ E-mail: myusingco@ateneo.edu
}

\section{Article Info}

Volume 1, Issue 2, September 2021

Received : 21 January 2021

Accepted : 18 August 2021

Published : 05 September 2021

doi: $10.51483 /$ IJPSPA.1.2.2021.25-33

\begin{abstract}
The digitalization of almost every aspect of civic life has brought forth a new democratic milestone with many people now having real-time access to information, to cultures beyond borders, and to discourses happening virtually any place in the world. This hyper-connectivity of people in the digital space has likewise put a new spotlight on the importance of constitutional rights such as free speech and press freedom, and its ability to foster community political engagement. Governments must keep social media a safe and vibrant space for citizen engagement and thus, must institutionalize measures against the deployment of online disinformation. To ensure the integrity of parliamentary democracy in the case of BARMM, three courses of action are proposed: the first being a youth-led comprehensive campaign on proper digital citizenship to empower social media users in the BARMM. The second is establishing clear guidelines in the soon-tobe enacted Bangsamoro Civil Code on the use of social media by government agencies and personnel in the region. And third is instituting prescriptions against disinformation in the impending Bangsamoro Electoral Code.
\end{abstract}

Keywords: Social media, Disinformation, Bangsamoro parliamentary elections

() 2021 Michael Henry LL. Yusingco. This is an open access article under the CCBY license (https://creativecommons.org/licenses/by/4.0/), which permits unrestricted use, distribution, and reproduction in any medium, provided you give appropriate credit to the original author(s) and the source, provide a link to the Creative Commons license, and indicate if changes were made.

\section{Introduction}

The internet is a technological innovation that provides people real-time access to information, to cultures beyond borders, and to discourses happening virtually any place in the world. As more people now interact in the digital world, the way they engage in their civic life has taken a new significance as well. The intense level of connectivity and the amplification of communication in cyberspace has put a new focus on constitutional rights such as free speech and press freedom, and its ability to foster community political engagement. And the central role of social media in contemporary society, particularly its ability to foster community political engagement, has heightened both criticism and appreciation for democracy itself.

For Filipinos the use of social media in the context of democratic practice is exceptionally remarkable because the Philippines has consistently placed first in social media use worldwide. Filipinos have also ranked high globally in internet usage with an average daily screen time of 10 hours. More importantly, a third of the 60+ million-strong Philippine electorate are from the 18-35 age bracket, where perhaps the majority of social media users actually belong.

\footnotetext{
* Corresponding author: Michael Henry LL. Yusingco, Ateneo Policy Center, School of Government, Ateneo de Manila University, Quezon City, 1108 Metro Manila, Philippines. E-mail: myusingco@ateneo.edu
} 
Remarkably, the number of social media users in the Bangsamoro Autonomous Region in Muslim Mindanao(BARMM) has increased despite the unreliability of internet coverage in Mindanao. Many civil society organizations working in the region have a strong online presence. Political personalities, including current members of the Bangsamoro Transition Authority (BTA), are likewise active in multiple social media platforms. Even the Bangsamoro government utilizes social media when livestreaming plenary sessions and committee hearings. Hence, it is only natural to wonder about the significance of a social media-savvy Bangsamoro electorate in the new autonomous region's first democratic test, the parliamentary elections in the BARMM in 2022.

Notably, political parties will take center stage in the BARMM parliamentary elections. This raises many questions as to how democratic this political exercise will be. Will political dynasties in the region lord it over as they do in the national elections? Can the political arm of the revolutionary fronts successfully parley their ideological zeal in the electoral arena? Will mainstream reformists be able to overcome accusations of being apologists for the powers-that-be in Manila?

These questions are extremely relevant because the Bangsamoro Parliament could be a carbon copy of the House of Representatives if electoral politics in the region just mirror that of the national level. A parliament dominated by dynastic interests will significantly diminish the chances of attaining peace and prosperity in the region as envisioned in the Bangsamoro Organic Law (BOL). Accordingly, would an online electoral dynamic in the region that evinces genuine democratic political party politics be an effective way of preventing this catastrophe?

Pertinently, during the midterm elections of 2019, CNN Philippines, through its Digital Disinformation Tracker research project, deployed a team of academics to monitor online conversations. And one of their findings was that practically all candidates used various social media platforms such as Facebook, Twitter and Instagram to promote themselves and their political agendas. This will likely happen in the 2022 parliamentary elections in the BARMM.

Ostensibly, social media enabled otherwise under-resourced citizens to run for public office. For instance, a majority of the 62 candidates in the 2019 senatorial race did not have nationwide popularity nor the proper election machinery to implement a conventional political campaign. Many of these relatively unknown candidates professed that social media platforms have afforded them the chance to raise their profile with minimal cost.

This apparent democratizing effect of social media then raises the question of whether a strong presence in social media equates to electoral success? First-time candidate Willie Ong is a good case study. At the time of the election, he had around 10 million followers on Facebook. As per the final and official tally of election returns, "Doc Willie", as he was known by his social media followers, garnered only about 7.6 million votes. This was not enough to get one of the 12 seats up for grabs. The candidate who got the $12^{\text {th }}$ seat tallied 14.5 million votes while the one who took the top spot received 25.2 million votes.

One possible reason why some popular online personalities did not perform well in the election was that Filipino voters pretty much stuck to their echo chambers in cyberspace. There was no effort from the various political sides to "reach across the aisle" so to speak. Each side was only keen to promote their respective narratives while equally determined to suppress the claims of the others. The problem with an "isolationist mindset" is how easily it can evolve into an "us versus them" mentality. Factor in the anonymity the internet affords, it is not surprising that interaction in social media can become really vitriolic quickly. In fact, another finding of the CNN Philippines research project was how "toxic" online discourse amongst the various political groups in social media was during the entire election period. Negative campaigning is part and parcel of any electoral exercise. Pointing out the faults and flaws of opposing candidates is not unusual and in fact, helps voters in evaluating whom to vote for. But according to veteran journalist and news anchor, Christian Esguerra, who covered the midterm election closely, "social media seemed to be a top weapon of choice for campaign disinformation, complementing old-school negative propaganda on the ground". Begging the question of whether more stringent measures regulating online political advocacies should be adopted? A move that ironically could be viewed as undemocratic being a curtailment of free speech.

Indeed, social media in the democratic context poses a huge dilemma for many democracies around the world. Fake news and other modes of disinformation on the web are preventing people from having an honest-to-goodness deliberation of urgent issues that impact everyone. This absence of open public discussion then enables purveyors of these types of unscrupulous tactics to put more garbage on the internet. Poisoning the well even further to the severe detriment of frequent social media users like Filipinos.

Clearly, the convergence of a young enthusiastic electorate and the pervasiveness of social media in the region necessitate an investigation on the possible impact of disinformation on the coming Bangsamoro parliamentary elections. This paper begins the discussion with a theoretical review of free speech and press freedom and why they must be 
protected in social media. This will then be followed by an examination of online disinformation. Particularly, how this internet phenomenon manifests in the Philippine context and how it can imperil the 2022 parliamentary elections in the BARMM. The second part of the discussion shall offer three courses of action to address disinformation in the BARMM in order to help ensure the democratic integrity of parliamentary politics in the region.

\section{Discussion}

\subsection{Part I}

\subsubsection{Free Speech and Press Freedom}

Social media is now a platform for all sorts of individual expression as well as a channel for news of every kind. It is a virtual bazaar of ideas, information and idiosyncrasies. Hence, any analysis of the impact of social media on democracy must begin with a review of the right to free speech and press freedom.

Freedom of opinion and freedom of expression constitute the cornerstone for every free and democratic society. Crucially, both rights are also integral to the enjoyment of the rights to freedom of assembly and association, and the exercise of the right to vote.

On the other hand, a free press is imperative for a society to fully enjoy freedom of opinion and expression. Indeed, the free communication of information and ideas about public and political issues between citizens and elected representatives is a bedrock of democracy. Press freedom therefore is essential for a democratic nation to thrive.

At the international level, Article 19 of the Universal Declaration of Human Rights provides:

Article 19: Freedoms of opinion and expression

1. Everyone shall have the right to hold opinions without interference.

2. Everyone shall have the right to freedom of expression; this right shall include freedom to seek, receive and impart information and ideas of all kinds, regardless of frontiers, either orally, in writing or in print, in the form of art, or through any other media of his choice.

Notably, the obligation to respect freedoms of opinion and expression covers all forms of opinion be it political, scientific, historic, moral, or religious in nature. ${ }^{1}$ Moreover, such forms include spoken, written and sign language, and non-verbal expression like images and objects of art. All means of dissemination under the second paragraph are protected. These include books, newspapers, pamphlets, posters, banners, legal submissions, and all forms of audiovisual as well as electronic and internet-based modes of expression.

On the domestic front, the 1987 Constitution prescribes that, "No law shall be passed abridging the freedom of speech, of expression, or of the press, or the right of the people peaceably to assemble and petition the government for redress of grievances." ${ }^{\prime 2}$ In the case of $A B S-C B N$ vs. Comelec, the Supreme Court ruled:

"The freedom of expression is a means of assuring individual self- fulfillment, of attaining the truth, of securing participation by the people in social and political decision-making, and of maintaining the balance between stability and change. It represents a profound commitment to the principle that debates on public issues should be uninhibited, robust, and wide open. It means more than the right to approve existing political beliefs or economic arrangements, to lend support to official measures, or to take refuge in the existing climate of opinion on any of public consequence. And paraphrasing the eminent Justice Oliver Wendell Holmes, we stress that the freedom encompasses the thought we hate, no less than the thought we agree with." ${ }^{3}$

The internet has allowed Filipinos to communicate to whomever they desire, as often as they want, at any time they feel like it, and wherever they may be situated. Clearly, social media can be a potent tool to deepen democracy in the Philippines. Making the protection of free speech and press freedom in this popular medium absolutely necessary. But digitalization also brings elements that endanger peoples and communities. In social media, this can come in the form of hate speech, cyberbullying and disinformation, just to name a few. Democracy itself is not immune from cyberattacks, as evidenced by Russian interference in the 2016 US presidential elections via a coordinated information laundering operation in social media platforms such Facebook and Twitter.

These bad elements in cyberspace moved many governments to institutionalize countermeasures. A United Nations counterterrorism official spoke in 2019 about terrorism threats in cyberspace, but here he expressed the sense of urgency

\footnotetext{
'Human Rights Committee, 102 ${ }^{\text {nd }}$ session, Geneva, July 11-29, 2011, General comment No. 34 accessible at https://www2.ohchr.org/ english/bodies/hrc/docs/gc34.pdf

${ }^{2}$ Article III, Section 4.

${ }^{3}$ G.R. No. 133486, January 28, 2000.
} 
that drives most governments to implement cybersecurity strategies, "They are constantly on the look-out to take advantage of any vulnerability or any possibility to exploit new technologies to recruit, communicate, finance themselves, plan and carry out attacks. We must come together now, and we must do it fast, to mitigate this threat and ensure that new technologies remain a force for good rather than a force for evil." 4

It has been observed however, that in the pursuit of ensuring digitalization continues as "a force for good rather than a force for evil", most governments implemented cybersecurity policies and legislation that may have actually undermined the very constitutional rights they aimed to uphold and protect. For instance, some laws have gone to the extent of criminalizing political dissent, while in some cases, even just the mere act of airing grievances against the government.

In fact, many democratic nation-states in this age of social media are precariously managing their commitment to uphold constitutional rights and their responsibility to ensure the safety and security of cyberspace for their citizens. In the United States for instance, the revelation that foreign adversaries have been using social media to sow political division has spurred an ongoing debate on whether social media companies should censure content posted in their platforms given that they are not actually bound by the demands of the First Amendment. In France, the Constitutional Council rejected a draft law that would have compelled social media giants such as Facebook and Twitter to remove any hateful content within 24 hours, ruling it interferes excessively in free speech. This temporarily halts President Emmanuel Macron's strong initiative to contain the spread of illicit content and false information in social media.

Nevertheless, it is clear that social media significantly impacts the trajectory of Philippine democracy. When utilized the right way, the "connectivity" it fosters can enhance political engagement within the polity, which then can elevate the level of political consciousness of Filipinos. Hence, the preservation of free speech and press freedom in social media must never be compromised. Bearing in mind though, the need to balance the often-clashing expectations of upholding the constitutional rights of citizens (or netizens in this particular case) and protecting them from the dangers operating in the digital world.

\subsubsection{Disinformation}

It is now universally accepted that online disinformation is the most insidious threat to democracy. The dictionary definition of disinformation is "false information deliberately and often covertly spread (as by the planting of rumors) in order to influence public opinion or obscure the truth". 5 This is to be distinguished from "misinformation" which is defined simply as "incorrect or misleading information". ${ }^{6}$ Both are obviously bad for democracy but it is the element of nefarious intent which makes disinformation the more fatal of the two.

To illustrate, the declaration of Ferdinand Marcos, Jr. in his resume that he had an undergraduate degree from Oxford and an MBA from Wharton can be classified as misinformation because Oxford University and Wharton School do not actually have his name in their lists of graduates. ${ }^{7}$ Whereas the falsehoods about the Marcos dictatorship being promoted by certain online sources can be classified as disinformation because their aim is to cover up the plunder and brutality perpetuated during Marcos' authoritarian regime. ${ }^{8}$

But it is not always easy to distinguish the two. For instance, the Philippine National Police reported recently that they arrested an "Abu Sayyaf sub-leader" in Basilan over the killing of a barangay official in 2014. Basilan Representative Mujiv Hataman disputed the characterization of this person as such claiming that he is in fact part of a community actively fighting the said terrorist group. ${ }^{9}$ The lawmaker wanted this alleged false information cleared up because it painted his province in a very bad light. But still, whether the police did this intentionally for this purpose remains to be determined.

Disinformation is a dangerous threat to democracy because information plays such a huge part in democratic consolidation, particularly in ensuring free and fair elections. Elections being a complex decision-making process regularly undertaken by a polity necessarily involves a reflective and rational public discourse about pressing issues and the viable policies to address them. Social media has profoundly transformed the character of this public political conversation because candidates (and political parties) can now extrapolate on a broader range of issues as well as reach out to multiple constituencies. However, as per Jonathan et al. (2019), the "dark side of this trend is the emergence of hyper-partisan platforms, such as closed Facebook groups and imposter news channels on YouTube,

\footnotetext{
${ }^{4}$ See https://www.un.org/sites/www.un.org.counterterrorism/files/20190926_usgvoronkov_statement_belarusside-event.pdf

${ }^{5}$ See https://www.merriam-webster.com/dictionary/disinformation

${ }^{6}$ See https://www.merriam-webster.com/dictionary/misinformation

${ }^{7}$ See https://www.rappler.com/newsbreak/investigative/bongbong-marcos-degrees-oxford-wharton

${ }^{8}$ See https://news.abs-cbn.com/spotlight/12/12/20/propaganda-web-pro-marcos-literature-sites-and-online- disinformation-linked

${ }^{9}$ See https://newsinfo.inquirer.net/1371230/pnp-wrong-in-tagging-murder-suspect-as-abu-sayyaf-sub-leader-solon
} 
that exploit citizens' mistrust against the political establishment in exchange for clicks that can be monetized through advertisements."

Disinformation in social media can indeed make election discourse hostile and toxic. This may come in the form of calculatingly abstruse communications, unfounded innuendo to cast doubt on the motives of political opponents, direct insults and other means of character assassination, falsehoods and other forms of misrepresentation of facts to confuse and mislead voters. Generally, the objective of a modern disinformation campaign is to pollute the public space to achieve a political outcome. Part of this modus operandi is to sow division among people by stoking emotions and prejudices with respect to a politically or socially charged issue.

There were glimpses of this partisan mudslinging and fearmongering during the campaign period for the ratification of the BOL. And it took tremendous effort on the part of the national government and the MILF to ensure that the BOL was properly and honestly explained to the Bangsamoro electorate. Supporters of the organic law left no stone unturned to make sure there were genuine deliberations at the grassroots level. Hence, it was not a surprise at all that an overwhelming majority of the Bangsamoro electorate came out and ratified the BOL. In a way, the campaign to ratify the BOL stands as a template for how the regional parliamentary election can be conducted.

It must be noted however that the employment of disinformation in politics is deliberate and strategic. Meaning, the purpose is to gain an upper-hand in the electoral contest. So, responses to such tactics would be as vicious and underhanded. When this happens, a genuine give and take within the electorate becomes virtually impossible. The campaign does not function as a venue for honest-to-goodness deliberations on problems and solutions, but instead it becomes an arena for political warfare. This can then amplify distrust in the integrity of elections and undermine the polity's confidence in the democratic process.

If disinformation takes control of the BARMM parliamentary elections, then it is very possible that the fractures in the region will get magnified. The infected political discourse could then focus on the differences that has plagued the region for so long, instead of galvanizing the polity towards the bright prospect of a shared prosperity promised by the BOL. The election would then be a winner-take-all proposition just like in the national level. The Bangsamoro Parliament could then end up being a mere clone of the House of Representatives, a chamber of dynastic interests. If this is the case, then the new regional government could become another "failed experiment".

\subsubsection{Philippine-Style Disinformation}

The deployment of disinformation for political gains is now a lucrative industry in the Philippines. The details of this new "business model" is chronicled in the 2018 book "Architects of Networked Disinformation: Behind the Scenes of Troll Accounts and Fake News Production in the Philippines" authored by Jonathan Corpus Ong and Jason Vincent A. Cabañes. Networked disinformation here means the "organized production of political deception that distributes responsibilities to diverse and loosely interconnected groups of hierarchized digital workers." Simply put, a disinformation assembly line.

At the top of the hierarchy is the chief digital strategist. These are highly trained professionals in the field of advertising and public relations. Their main responsibility is to generate and inspire support through online engagement. Their task is to assemble a team of digital influencers and fake account operators. Digital influencers are "online microcelebrities who maintain humorous and compelling digital personas that attract between 50,000 and 2,000,000 followers." During campaign periods, their pages are "activated" to promote hashtags and memes favorable to the client candidate. At the bottom of the disinformation totem pole are the "lower-level workers who operate fake accounts on Facebook and Twitter". Their work consists of posting positive messages of support for their principal and initiating quarrels with supporters of rival politicians. Their most favored weapons are ad hominem attacks and denigrating other people's bad grammar. In sum?

"The aim of architects of networked disinformation then is to ignite support at the grassroots level and harness the impassioned zeal of "real" political supporters to take on the work of persuasion in everyday spaces and rhythms of social media. But in order to achieve emotionally resonant messaging and authentic branding that would trigger grassroots support, chief disinformation architects need to collaborate with influencers much more fluent in popular vernaculars when planning creative executions of digital campaigns. Strategists and influencers then harness the support of both community-level fake account operators tasked to generate momentum and energy for a campaign and create "illusions of engagement". Then, unpaid grassroots intermediaries and "real" supporters who operate like political fans amplify original campaign messages through shares and likes-but also take them forward in unpredictable ways." 
The peddling of disinformation in politics is now a huge revenue earning sector. Adding another layer of evil to the scourge of money politics in the country. It would not be a surprise at all if some of these disinformation professionals are already plying their trade in the BARMM. Some may even be gearing up for the 2022 parliamentary elections. Hence, the need for defense measures against disinformation to be set up in the BARMM. Clearly, there is urgency in protecting the Bangsamoro polity because it is now palpably even more active in social media.

\subsection{Part II}

A high level of citizen engagement in the political arena is a sign of a healthy democracy. Hence, it is in the best interest of a democratic nation-station to foster and even encourage political activism in social media. This is precisely the reason why protecting free speech and press freedom in social media is extremely vital. More importantly, it is likewise imperative for governments to keep social media a safe and vibrant space for all kinds of citizen engagement. Hence, the need to institutionalize mechanisms against the deployment of online disinformation.

As previously mentioned, many democratic governments are still struggling with balancing between the need to keep social media a democratic space and the duty to protect their citizens thriving in this new medium. The most common mechanism employed by governments is anti-cybercrime legislation. For the Philippines, this is Republic Act No. 10175 or Cybercrime Prevention Act of 2012. This law became controversial under the Duterte administration for its use against both critics and hecklers of the government.

Some view this law as antiquated and thus needs urgent updating for it to successfully address new threats in cyberspace. Obviously, the bad elements spoiling the internet have become deadlier in their sophistication. This is very clear now with how the deployment of disinformation infects democracy. As per Jonathan and Jason (2018), the architects of networked disinformation "exploit their understanding of the public's ways of engaging with political personalities and issues. Most perniciously, the populist style that influencers use to spark divisive discussions and fan the flames of discontent inevitably normalizes and amplifies toxicity in public discussions."

Clearly, to ensure the integrity of parliamentary democracy in the BARMM, measures must be put in place to fight the scourge of disinformation in the region. Three courses of action are proposed here, the first being a massive and comprehensive campaign on proper digital citizenship to empower social media users in the BARMM. The second is establishing clear guidelines on the use of social media by government agencies in the region. And third is instituting prescriptions against disinformation in the impending Bangsamoro Electoral Code.

\subsubsection{Digital Citizenship}

According to the United Nations Educational, Scientific and Cultural Organization (UNESCO), "digital citizenship is a set of skills that enables citizens to access, retrieve, understand, evaluate and use, to create as well as to share information and media in all formats, using several tools, in a critical, ethical and effective way to participate and engage in personal, professional and social activities." In simple terms, it is the ability of an individual to engage in social media in a civil and critical way.

The purpose of digital citizenship is to uphold norms of appropriate and responsible use of digital technology. As previously mentioned, the challenge is to maximize the democratic potential of the digital public sphere while defending against threats that pose significant harm to the polity. Digital citizenship imposes on social media users a responsibility to vet information acquired through this medium. Correspondingly, the social media using public should be accountable for the sharing of false or malicious information in cyberspace.

It must be clarified though that a digital citizenship regime does not absolve government from any responsibility in preserving the safety and security of the online world. It merely highlights the reality that the polity must do its part to regulate cyberspace such as upholding free speech standards in social media. In fact, the idea of digital citizenship shows that keeping the virtual realm as a vibrant and democratic space requires the collaboration of government and civil society. The proposal to promote digital citizenship in the BARMM proceeds from this very premise.

Truth be told, digital citizenship is urgent not just in the BARMM, but for the entire country as well. A recent study from the Ateneo de Naga University (AdNU) showed "Higher Education Institution (HEI) students from Bicol also struggled in skills related to debunking disinformation such as verifying authentic Facebook $(\mathrm{FB})$ pages and differentiating facts from opinion." ${ }^{10}$ To combat disinformation, the study suggests, "A combination of heuristic, systematic information processing strategies, critical thinking skills, and journalism code of ethics must be included in a media or literacy

\footnotetext{
${ }^{10}$ See https://news.abs-cbn.com/spotlight/12/18/20/higher-education-students-in-bicol-cant-distinguish-news-from- paid-articles-study
} 
curriculum." In short, academic institutions in the country, including those in the BARMM, must now institutionalize digital citizenship programs for their students. ${ }^{11}$

But there is another agency in the BARMM which can arguably be more effective in furthering digital citizenship in the region and this is the Bangsamoro Youth Commission (BYC). Social media is essentially the domain of the youth, hence, it only makes sense that efforts to establish digital citizenship in the BARMM be youth-led. Moreover, Bangsamoro Act No. 10, which created the BYC, provides that it is the policy of the Bangsamoro government to encourage youth involvement in public and civic affairs and that this office is mandated to conduct trainings, seminars and workshops to enhance the skills and leadership potential of Bangsamoro youths. ${ }^{12}$

Indeed, the BYC is in the best position to design the content of a comprehensive digital citizen education campaign and ensure that the same is appropriate for the BARMM. More importantly, it already has an existing network that can ensure the program reaches young people in every nook and cranny of the region. A well-crafted and properly executed digital citizen education program in the BARMM can help fight against the deployment of disinformation in the region. Needless to say, this can be a huge assistance in the effort to protect Bangsamoro youths from recruitment by violent extremist groups. Clearly, the Bangsamoro youth must flex their power in the lead up to the parliamentary election in 2022 , in the same way they did for the ratification of the BOL. Plainly, it is in their best interest to do whatever it takes to prevent the Bangsamoro Parliament from becoming a carbon-copy of the national Congress.

\subsubsection{Government Social Media Use}

According to David et al. (2019) netizens following public officials or institutions on Facebook is usually associated with higher levels of political interest and involvement. Meaning, the use by government agencies of social media as a way of conveying information fosters a closer connection with the public. And citizens obviously engage more actively with their government being present in cyberspace. This correlation is perfectly illustrated by the Bangsamoro government's regular livestreaming of their plenary sessions and committee hearings in its Facebook account.

In the Philippines however, the government's use of social media platforms has been plagued by controversy with some high-profile agencies being accused of spreading disinformation. Case in point is the one cited earlier about a police report on the arrest of a purported "Abu Sayyaf sub-leader" but which was adamantly disputed by Deputy Speaker Mujiv Hataman. Red-tagging, or the arbitrary association of individuals to communist armed groups, employed by national security agencies is another vile example of purveying online disinformation. In this case, the consequences can be fatal, as evidenced by the struggles of Non-Moro Indigenous Peoples in Mindanao under the Duterte administration. ${ }^{13}$ And it is worth reiterating that the misuse of official social media channels can compromise national security and undermine public order.

The reality is that citizens rely on their government to be the source of facts and truths. Life-changing decisions are made based on information and data sourced from government officials and offices. Therefore, the use of social media platforms by state institutions and civil servants must be strictly regulated. Obviously, designated guidelines should also cover elected officials utilizing social media to reach out to their constituencies.

For the BARMM, the upcoming Bangsamoro Civil Service Code should provide prescriptions mandating that official social media accounts must only communicate official business and must not be used for any other purpose. Additionally, the assigned handlers of social media accounts must at all times treat the public with utmost respect and courtesy. But most critical of all, the Bangsamoro government's social media team must have the wherewithal to convey important messages in a controlled and reassuring way.

The code must likewise impose an administrative penalty to officials and/or employees found to be spreading disinformation in official or personal social media accounts. In this regard, the code must also prescribe that BARMM officials and employees must at all times display the proper decorum in their social media behavior to preserve the dignity of the office or position they hold or represent.

It cannot be emphasized enough that public officials in social media offers a lot of benefit in terms of deepening democracy and therefore must be encouraged in the BARMM. A good example here is the Office of MP Maisara Damdamun-Latiph with their quarterly digital newsletter, 'Empowering Voices', which aims to provide relevant and timely information about pressing issues in the BARMM as a way to fight the proliferation of fake news in social media. ${ }^{14}$

\footnotetext{
${ }^{11}$ See https://cmfr-phil.org/in-context/knowing-your-source-think-before-you-click/ and https:/www.digitalcitizenship.nsw.edu.au/articles/ become-a-discerning-digital-citizen

12 See Sections 2 and 8.

${ }^{13}$ See https://www.lowyinstitute.org/the-interpreter/philippines-activists-increasingly-face-living-hell

${ }^{14}$ See https://www.pna.gov.ph/articles/1105567
} 
But this inherent advantage of incumbents comes with the responsibility of ensuring no disinformation or misinformation are ever deployed from their social media accounts. And there should be a price to pay for those public officials and civil servants in the region found to be remiss in fulfilling this duty.

\subsubsection{The Bangsamoro Electoral Code}

Social media will definitely be at the forefront in the 2022 elections. Political activities in this medium will likely intensify once the election period officially begins. But glimpses of political gimmicks can be seen now in social media. These early-bird online self- promotion drives are tacky but not illegal. Nonetheless, there is still an urgency to institute measures to ensure the sanctity and safety of the digital space in relation to the electoral process. For the BARMM, this would entail incorporating in the impeding Bangsamoro Electoral Code prescriptions that would defend the Bangsamoro electorate against the onslaught of disinformation in social media leading up to the parliamentary election.

For instance, the electoral code should establish a dedicated social media desk in the regional election office whose task is to do real time monitoring of election related activities online and pro-actively respond to emerging issues with political independence. Additionally, the code should also penalize the deployment of disinformation conclusively attributed to individual candidates and political parties.

This regional election statute should require all candidates and political parties to have an official website. They must bear the responsibility for all information coming out of their camps. In this regard, all official campaign materials must display a stamp or declaration of approval by the candidate and/or the political party.

Lastly, the Bangsamoro Electoral Code must impose stricter election campaign finance regulation which should include digital campaigning. The Bangsamoro electorate has the right to know the full extent of campaign spending across both traditional and new media platforms. Specifically, the money they have spent on viral videos, trending hashtags, and Facebook advertisements. These measures can insulate online political campaigning in the BARMM from the operators of disinformation networks.

The high stakes of the parliamentary elections in the BARMM cannot be emphasized enough. The prospect of the region attaining the goals set by the BOL depends squarely on the quality of the first elected parliament in 2022. All efforts must now be exerted to ensure that the Bangsamoro electorate have a clear-eyed view of politicians and political parties vying to be part of that august body. It is imperative therefore that the BTA enact a Bangsamoro Electoral Code that protects the digital space against disinformation. Failure to do this just heightens the risk of unworthy individuals and sham political parties being elected in the Bangsamoro Parliament, thus increasing the likelihood that it will be a mere mirror image of the House of Representatives.

\section{Conclusion}

The Covid-19 global pandemic has severely restricted the mobility of peoples around the world. Accordingly, 2021 for the country is expected to be the year of digitalization. Bringing to the fore the government's duty to stand out as an exemplary user of social media and the urgency of meeting its evident responsibility to preserve this medium as a safe and democratic space for all.

The reality is social media is now a site where citizens learn about public affairs and where they deliberate and mobilize political action. Thus, there can no longer be any doubt that a social media-savvy Bangsamoro electorate will be a huge factor in the very first parliamentary elections in the BARMM in 2022.

It is a sad reality though that online disinformation is now deemed the most insidious threat to democracy. Disinformation in social media can make election discourse hostile and toxic. Under these conditions, political campaigning no longer provides the opportunity for an honest-to-goodness public accounting of problems and solutions. This electoral exercise actually becomes a vehicle for political warfare between political protagonists. A dire prospect that must be avoided in the BARMM parliamentary election given the volatility of politics in the region.

Nevertheless, political activism in social media needs to be fostered. This is precisely the reason why protecting free speech and press freedom in social media is still a noteworthy task. Governments must keep social media a safe and vibrant space for citizen engagement and thus, must institutionalize measures against the deployment of online disinformation.

To ensure the integrity of parliamentary democracy in the BARMM, three courses of action have been proposed here, the first being a youth-led comprehensive campaign on proper digital citizenship to empower social media users in the BARMM. The second is establishing clear guidelines in the soon-to-be enacted Bangsamoro Civil Code on the use 
of social media by government agencies and personnel in the region. And third is instituting prescriptions against disinformation in the impending Bangsamoro Electoral Code.

These measures are designed to safeguard the sanctity of the first parliamentary elections in the BARMM. They are meant to protect the Bangsamoro electorate from the perils of disinformation in social media. But they also signify the need for government and civil society to work together to ensure democratic principles reign true in the digital space.

Admittedly, the BTA has a lot of work to do in terms of improving internet connectivity in the region. The benefits of digitalization should not be limited to the urban areas of the BARMM. But foremost of all, the BTA must guarantee for everyone in the region, that the digital world will be secure against all forms of cyberthreats, most especially online disinformation.

\section{References}

Cherilyn, Ireton., and Julie, Posetti. (Eds.) (2018), Journalism, Fake News \& Disinformation: Handbook for Journalism Education and Training, accessible at https://unesdoc.unesco.org/ark:/48223/pf0000265552

Clarissa, C. David., Ma. Rosel S., San Pascual., and Ma, Eliza S. Torres. (2019). Reliance on Facebook for News and its Influence on Political Engagement, accessible at https://journals.plos.org/plosone/article?id=10.1371/ journal.pone. 0212263

Daniel, Kats. (2020). Identifying Sockpuppet Accounts on Social Media Platforms, April 30, accessible at https://www. nortonlifelock.com/blogs/research- group/identifying-sockpuppet-accounts-social-media

Darrin, Durant. (2020). Disinformation and the Challenge to Democracy, accessible at https://eng.unimelb.edu.au/industry/ defence/news-and-events/disinformation- and-the-challenge-to-democracy

Imitiaz, Khan., and Ali, Shahaab. (2020). Lessons from Estonia, the World's Most Digitally Advanced Nation, October 18, accessible at https://www.channelnewsasia.com/news/commentary/estonia-most-digitally-savvy- countryelectronic-citizenship-13281738

Jonathan, Ong., and Jason, Vincent, A. Cabañes. (2018). Architects of Networked Disinformation: Behind the Scenes of Troll Accounts and Fake News Production in the Philippines, accessible at https://scholarworks.umass.edu/ communication_faculty_pubs/74/

Jonathan ,Ong., Ross, Tapsell., and Nicole, Curato. (2019). Tracking Digital Disinformation in the 2019 Philippine Midterm Election, accessible at www.newmandala.org/disinformation

Laura, Thornton. (2020). Democracy's Biggest Challenge is Information Integrity, November 13, accessible at https:// www.neweurope.eu/article/democracys-biggest-challenge-is-information-integrity/?fbclid=Iw AR2EDZFXjEXGTJVgeg- qe 55tceicDBPzhPR0yF7vfoVR6pJtTjp3OYaD1Pk

Ram, Superable, Agustin. (2020). Survey: Social Dummy Accounts Growing in Numbers, December 11, accessible at https://newsbytes.ph/2020/12/11/survey-social-dummy-accounts-growing-in-numbers/?fbclid=IwAR21Hrg SubN8ifA2jQPNMAKYSVqTK7KEPU8b1HVUj3OE_o-Dv-fiqRZoRag

Timothy, Graham., Axel, Bruns., Daniel, Angus., Edward, Hurcombe., and Sam, Hames. (2020). \#IStandWithDan versus \#DictatorDan: The Polarised Dynamics of Twitter Discussions about Victoria's COVID-19 restrictions, December 20, accessible at https:/journals.sagepub.com/doi/full/10.1177/1329878X20981780

Tony, Tran., and Yael, Bar-Tur. (2020). Social Media in Government: Benefits, Challenges, and How it's Used, March 26, accessible at https://blog.hootsuite.com/social- media- government/\#: :text=On\%20social\%2C\%20people\% 20can\%20engage,a $\% 20$ chance $\% 20$ to $\% 20$ engage $\% 20$ back.\&text=That's\%20why\%20we\%20want $\% 20$ to, building $\% 20$ awareness $\% 20$ to $\% 20$ crisis $\% 20$ communication

Wafa, Ben-Hassine. (2021), Government Policy for the Internet Must Be Rights-Based and User- Centred. Accessible at https://www.un.org/en/chronicle/article/government-policy-internet-must-be-rights-based-and-user-centred

Cite this article as: Michael Henry LL. Yusingco. (2021). Social M edia, Disinformation, and the 2022 BA RM M Parliamentary Elections. International J ournal of Pol itical Scienceand Public A dministration, 1(2), 25-33. doi: 10.51483/ IJPSPA.1.2.2021.25-33. 